\title{
FLUTUAÇÃO DA POPULAÇÃO DE FUNGOS SOB FLORESTA OMBRÓFILA MISTA E EM POVOAMENTO DE Pinus taeda
}

\author{
Flora Osaki ${ }^{1}$, Sylvio Péllico Netto ${ }^{2}$ \\ ${ }^{1}$ Eng $^{\mathrm{a}}$ Agrônoma, Dr ${ }^{\mathrm{a}}$. , Curso de Agronomia, PUCPR, Curitiba, PR, Brasil - rk_osaki@ netpar.com.br \\ ${ }^{2}$ Eng. Florestal, Dr., Depto. de Ciências Florestais, UFPR, Curitiba, PR, Brasil - sylviopelliconetto@ gmail.com
}

Recebido para publicação: 12/08/2011 - Aceito para publicação: 05/09/2012

\begin{abstract}
Resumo
O presente trabalho teve como objetivo avaliar a distribuição vertical e horizontal da população de fungos numa Floresta Ombrófila Mista e num povoamento florestal com Pinus taeda , separadamente. O experimento foi realizado em Tijucas do Sul, PR. Os tratamentos constituíram-se de dois fatores, com três repetições. Para o primeiro fator, foram estudadas três profundidades: serapilheira, zona de transição e solo, e para o segundo fator foram as estações do ano (inverno e verão). A topossequência da Floresta Ombrófila Mista foi dividida em plana, meia encosta e topo, e em cada uma delas foi alocado um bloco de $10.000 \mathrm{~m}^{2}$, subdividido em cem subunidades. Foram sorteadas aleatoriamente cinco subunidades amostrais, que compuseram as amostras simples, que, sendo homogeneizadas, formaram uma unidade amostral composta por bloco. O relevo da área do povoamento florestal com pínus caracterizou-se como plano, sendo adotado o mesmo procedimento para implantação dos blocos e da coleta das unidades amostrais. A análise da população de microrganismos mostrou diferença entre as profundidades, sendo maior na serapilheira e no verão. Para o povoamento com pínus, a população de fungos não mostrou diferenças entre estações, sendo maior na serapilheira. A população de fungos foi superior na Floresta Ombrófila Mista. Palavras-chave: Pínus; microbiota; serapilheira; solo; fertilidade.
\end{abstract}

\begin{abstract}
Fungi population variation under the Subtropical Ombrophilous Forest and Pinus taeda plantation. This paper aims to evaluate vertical and horizontal distribution of fungi population in Subtropical Ombrophilous Forest and Pinus taeda plantation, separately. The experiment had been improved in the municipality of Tijucas do Sul, PR, with 2 factors and 3 replications. The evaluated factors were depth (litter, transition zone and soil) and seasons (winter and summer). The Subtropical Ombrophilous Forest toposequence was divided in plain, hillside and top, where it was placed a $10,000 \mathrm{~m}^{2}$ plot; which was subdivided in one hundred subplots. It was selected five alleatory samples which composed the simple samples, and, as they were randomized, they composed one block sample unit. The P. taeda plantation exhibited a topographic sequence that was classified as plain, and the same topography was used for the following sampling. The microorganism's population analyses revealed differences between depths, it was higher in the litter and in the summer. The fungi population presented no differences between seasons in the $P$. taeda plantation, it was higher in the litter. It was identified a higher fungi population in the Subtropical Ombrophilous Forest compared to the results observed in the plantation. Keywords: Pinus; microbiot; litter; soil; fertility.
\end{abstract}

\section{INTRODUÇÃO}

O estado do Paraná, em 1930, apresentava 64\% de cobertura florestal nativa, sendo que o fomento da agricultura, principalmente o café, na década de 60, resultou no desmatamento de grandes áreas de floresta. Em 1965, a área de cobertura florestal era de $24 \%$ e, atualmente, o estado conta com apenas $17 \%$ de cobertura florestal (CAMPOS, 2008). Por outro lado, as atividades de reflorestamento estão em expansão. O reflorestamento no Brasil foi iniciado na metade do século 20, sendo que, com o esgotamento da exploração madereira sustentável em torno de 1964, o desenvolvimento da silvicultura foi impulsionado, em função da demanda internacional por produtos de base florestal. De acordo com dados 
do Instituto Ambiental do Paraná (IAP) (2006), o principal gênero plantado no estado do Paraná é o Pinus sp., que em 2005 totalizou 677 mil hectares plantados.

Assim, independentemente da origem da floresta, a importância dela, quando não alterada em sua estrutura, está no fornecimento de matéria-prima e na manutenção da biodiversidade, do clima e do solo. A produtividade dessas florestas é decorrente das condições ambientais existentes, cujos fatores biofísicos e biológicos do sítio interagem entre si. Os fatores ligados ao solo e à ciclagem biológica são os principais responsáveis pelo estado nutricional aparente do maciço florestal (GONÇALVES et al. 1990; REISSMANN; WISNIEWSKI, 2000).

Entre os processos mais significativos, destaca-se a atividade das biotas do solo, sobretudo dos fungos, que mantêm estreita relação com sua fertilidade, calor e umidade, tendo em vista sua importante participação na ciclagem de nutrientes (BROWN; LUGO, 1982; SAMPAIO et al., 1993).

A população microbiana varia de acordo com as características das espécies vegetais, edáficas e climáticas específicas de cada ambiente (MOREIRA; SIQUEIRA, 2002).

Os fatores climáticos influem na velocidade e no vigor da hidratação, oxidação e hidrólise, entre outros processos químicos do solo (MOREIRA; SIQUEIRA, 2002). Além disso, a estação climática (verão, outono, inverno e primavera) condiciona o tipo de revestimento vegetal e o seu dossel, principal matéria-prima para a formação da serapilheira e da elaboração da matéria orgânica.

Temperaturas de 28 a $35{ }^{\circ} \mathrm{C}$ e umidade próxima à capacidade de campo favorecem as reações físicas e químicas, maximizando as atividades microbiológicas (MOREIRA; SIQUEIRA, 2002). Rigobelo e Nahas (2004) relatam maior acumulação de serapilheira para a estação das chuvas e, consequentemente, aumento da biomassa vegetal de pínus. Essas condições propícias favorecem as taxas de reação microbianas, sendo maiores em temperaturas próximas à $28{ }^{\circ} \mathrm{C}$, decrescendo em temperaturas menores que 25 e maiores que $35^{\circ} \mathrm{C}$ (MOREIRA; SIQUEIRA, 2002). A estação influencia a população microbiana, resultante da maior ou menor quantidade de resíduos que caem sobre o solo. Portanto, a temperatura influi nas reações fisiológicas, como também nas características físico-químicas do solo e, consequentemente, no ambiente onde vivem os microrganismos (HEANEY; PROCTOR, 1989; BRITEZ, 1994; SANTOS; CAMARGO, 1999).

Em relação à umidade, um estudo realizado por Souto (2006), avaliando o comportamento ecológico de fungos na RPPN pertencente à Fazenda Tamanduá, em área de 381,6 ha, localizada no município de Santa Terezinha, região da Caatinga, na Paraíba, observou que a redução do conteúdo de água no solo promoveu decréscimos consideráveis na população fúngica, enquanto que o aumento das precipitações, em junho e julho/2004, elevou o conteúdo de água no solo em torno de $10 \%$, favorecendo o aumento da população. Além da influência da umidade no desenvolvimento da comunidade fúngica, Souto (2006) verificou maior população de fungos no mês de novembro/2003, atribuindo esse acréscimo ao aumento da matéria orgânica na superfície e ao maior teor de umidade nesse período.

Segundo Freire (1975), a estação do ano tem influência correlacionada com a temperatura, disponibilidade de matéria orgânica e umidade. Os períodos sazonais, mais especificamente a temperatura, têm influência primordial sobre os fungos, pois em geral são mesófilos. Poucos são termófilos, e estes têm sua atividade nos compostos. Essas temperaturas eliminam muitas outras espécies microgênicas, permitindo a sobrevivência dos microrganismos termófilos. Temperaturas muito altas podem flocular alguns componentes orgânicos e insolubilizar proteínas hidrossolúveis, além de desprender amônia se o composto estiver na fase de amonização do nitrogênio orgânico, afetando os microrganismos. Por isso, na camada da serapilheira, mesmo a temperatura atingindo níveis de até $35^{\circ} \mathrm{C}$, os microrganismos sobrevivem e se multiplicam, mostrando a grande adaptação que os fungos possuem, como é o caso do Aspergillus e do Trichoderma. São mais numerosos nas camadas da serapilheira, momento em que se tornam mais ativos, razão pela qual permanecem em materiais onde recebem mais calor e umidade e que coincide com o período de verão, concordando com os dados obtidos neste trabalho.

O efeito do calor pode estar ligado à disponibilidade de matéria orgânica no caso serapilheira e à adaptação à baixa pressão do $\mathrm{O}_{2}$ ou à alta concentração de $\mathrm{CO}_{2}$, proveniente da atividade respiratória dos microrganismos. Já no inverno, as camadas superficiais ficam muito frias e certos fungos são associados especificamente a certas espécies vegetais, que se desenvolvem bem no inverno, demonstrando a ação seletiva que possuem. Presume-se que essa ação seletiva dos microrganismos deva ser consequência do tipo de vegetação e das secreções radiculares eliminadas nesse período, ou da pré-decomposição química 
de materiais que caem no verão e se disponibilizam no solo superficial, onde as temperaturas lhes são mais favoráveis e constantes nesse período.

Em regiões temperadas, a população microbiana do solo aumenta na primavera e outono, e diminui no inverno e verão seco. Em regiões tropicais, a população aumenta nos períodos de chuva e diminui nos períodos de seca (FREIRE, 1975; ALEXANDER, 1980). Regiões subtropicais favorecem a degradação dos resíduos culturais, aumentando a população microbiana na primavera e outono e diminuindo no inverno e verão seco, porque as reações bioquímicas reduzem-se e a população microbiana do solo tende a ficar inativa (CATTELAN et al., 1997).

Os fungos são decompositores lentos em períodos sazonais frios de regiões subtropicais, resultando na formação de húmus em maior quantidade, quando comparados com outros microrganismos, e podem se desenvolver melhor em solos mais secos do que as bactérias. Espécies de fungos e bactérias esporulantes, como é o caso do Clostridium, toleram potenciais hídricos bem menores que bactérias não esporulantes, como o Rhrizobium, porque os esporos são estruturas de tolerância a diversos estresses. Solo demasiadamente seco causa a morte de células vegetativas, aumentando a esporulação e garantindo a sobrevivência (HARRIS, 1981; PAUL; CLARK, 1989).

No solo são encontrados, em geral, em densidades populacionais abaixo das bactérias e actinomicetos, variando de $10^{4}$ a $10^{6}$ unidades. g $^{-1}$ de solo, contribuindo em geral com a maior parcela da biomassa microbiana (DIONÍSIO, 1996). Os fungos representam em média $2 / 3$ da biomassa microbiana, têm relação $\mathrm{C} / \mathrm{N}$ em cerca de 10 e convertem $44 \%$ do carbono (C) prontamente decomponível a tecidos microbianos (MOREIRA; SIQUEIRA, 2002).

Os fungos obtêm energia e carbono de compostos orgânicos e são aeróbios obrigatórios. São também importantes agentes de controle biológico de outros fungos e nematoides fitopatogênicos. São, ainda, organismos heterotróficos quimiorganotróficos, que podem ser saprófitos sacarídeos (ficomicetos), degradadores de lignina (basidiomicetos), coprófilos (estrumes), predatórios e habitantes radiculares. Sendo assim, possuem diversas funções no solo: decomposição de resíduos orgânicos; agentes de controle biológico e formadores de simbioses mutualísticas com plantas (micorrizas) e algas verdes ou cianobactérias (líquens).

A serapilheira apresenta quantidades de nutrientes significativas, que são mineralizados pela atividade microbiana, principalmente pelos fungos. Assim, Ghizelini (2005) estudou a sucessão de fungos em acículas de $P$. taeda L. durante um período de doze meses e buscou estabelecer uma relação entre a presença dos fungos e as condições climáticas locais, no município de Três Barras/SC. Durante o trabalho, foram identificados 13 gêneros fúngicos, com maior número total de registros em novembro e fevereiro e o menor em maio, sendo este último referente ao mês de menor temperatura.

A dinâmica da população microbiana na decomposição da serapilheira foi estudada por Selle (2007), que considera, de forma semelhante aos demais autores, que climas mais secos e com temperaturas mais elevadas resultam no acúmulo da serapilheira, com a decomposição ocorrendo com maior rapidez e maior disponibilização imediata dos nutrientes em locais onde ocorrem maiores precipitações.

A vegetação e o clima também governam a variabilidade horizontal dos materiais que caem sobre o solo, a denominada serapilheira, mostrando ainda que, quanto maior a diversidade da comunidade vegetal, mais heterogênea será a serapilheira em pontos adjacentes. Entretanto, a heterogeneidade vertical da serapilheira, isto é, a formação diferenciada das camadas ou horizontes, é consequência da velocidade de decomposição (SANTOS; CAMARGO, 1999). O material vegetal que forma a serapilheira de um solo sob floresta, seja natural ou plantada, é uma mistura de vários componentes da estrutura da planta: troncos, galhos, folhas, flores, frutos, sementes e acículas.

A vegetação e as suas raízes são, ainda, fontes de carbono no solo, que estimulam a atividade dos microrganismos, colocando o ecossistema em uma nova situação de equilíbrio (BALOTA; ANDRADE, 1999). A decomposição dos resíduos se dá de acordo com fatores específicos de cada um dos seus componentes principais, já que estes variam segundo a sua forma de assimilação ou persistência no solo. Os resíduos vegetais ditos "prontamente assimiláveis" são os substratos considerados não persistentes e cuja assimilação lenta permite sua acumulação no solo, no qual se estabilizam (MOREIRA; SIQUEIRA, 2002).

Essa diversificação ocorre devido às características próprias das estruturas químicas das moléculas, a bioquímica (enzimas e rotas degradativas) e a capacidade degradadora dos microrganismos, 
além das funções no tecido vegetal, como no caso da celulose, que compõe a parede celular. Também a maior ou menor concentração de determinados componentes faz o material degradar mais rápido ou mais lentamente. A celulose, por exemplo, é decomposta em menos de um ano, enquanto outras frações resistem à decomposição. Materiais constituídos de teores elevados de lignina são de difícil decomposição, persistindo por mais tempo no solo. A lignina, a casca de madeira, a turfa e acículas de pínus são consideradas recalcitrantes e, pelo seu acúmulo no solo, imobilizam carbono e nutrientes (FREIRE, 1975; SANTOS; CAMARGO, 1999; MOREIRA; SIQUEIRA, 2002).

A diversidade espacial e temporal da comunidade fúngica de ecossistemas florestais, sejam naturais ou plantados, tornam o seu estudo mais complexo. A análise da distribuição da população fúngica depende das técnicas utilizadas para sua determinação e também da representatividade das amostras (CALBRIX, et al., 2005).

Em trabalho realizado por Valpassos et al. (2007), foram estudados três sítios: uma área degradada que foi reflorestada com Corymbia citriodora (Hook) K. D. Hill \& L. A. S. Jonhson e Leucaena leucocephala (Lam.) de Wit, um sítio onde houve a remoção da vegetação e do solo e outra área dentro da Floresta Atlântica, todas localizadas na Ilha Solteira/SP, com o objetivo de estudar a recuperação da área pela avaliação das comunidades microbianas e sua atividade. Os autores verificaram que as áreas vegetadas apresentaram as maiores populações de bactérias, fungos, actinomicetos e oxidadores de nitrito, sugerindo que o efeito combinado do tipo de vegetação e a degradação da matéria orgânica justificam o maior número de microrganimos nas áreas florestadas.

Santos e Camargo (1999), estudando a decomposição de folhas de diferentes espécies de leguminosas, observaram que a maior influência no substrato foi provocada pelos materiais que apresentavam teores de compostos fenólicos, do que por aqueles com teores de nitrogênio ou lignina, sugerindo que estes, ligados àqueles, são de difícil decomposição.

A degradação da lignina no solo se dá em geral por fungos especializados, da ordem Agaricales, como basidiomicetos e determinados ascomicetos, sendo representantes o Pleurotus ostreatus e o Phanerochaete versicolor, que podem degradar tanto a lignina quanto a celulose. Além desses, o Phanerochaete chrysosporium é típico decompositor da lignina (MOREIRA; SIQUEIRA, 2002).

Um fator importante que se destaca na atividade dos microrganismos do solo é a profundidade. Normalmente, a matéria orgânica diminui abaixo do horizonte A e, como existem mais alimentos e fontes energéticas mais abundantes nele, há aí aumento da população microbiana. Além dessa condicionante, podem ocorrer grandes variações entre ecossistemas distintos, mesmo estando na mesma região ou em distintas regiões geográficas, ou ainda variações decorrentes de sistemas de cultivo, se natural ou plantado (FREIRE, 1975; MOREIRA; SIQUEIRA, 2002).

Uma população de microrganismos influencia a vida populacional da estação seguinte, seja por uma maior ou menor quantidade de resíduos devolvidos ao solo, seja por uma maior ou menor quantidade de microbiotas (FREIRE, 1975).

Nas diferentes formações florestais, seja de Floresta Ombrófila Mista ou Povoamento com $P$. taeda, a maneira da matéria orgânica se incorporar é de cima para baixo, acumulando-se na superfície do solo a serapilheira, que forma os horizontes orgânicos, cuja função é o equilíbrio entre entradas e saídas do sistema. Referem-se à entrada os materiais que entram através da deposição da serapilheira, e à saída, a transformação deles através da decomposição que ocorre quase simultaneamente (PEÑA, 2002; SANTOS; CAMARGO, 1999). Assim, quanto mais se deposita a serapilheira e quanto menor for sua velocidade de decomposição, mais espessa ela será (SANTOS; CAMARGO, 1999).

O processo de decomposição, ao longo do tempo, forma um gradiente, em que as folhas recémcaídas se caracterizam por apresentar pouca transformação. Já as mais antigas apresentam um alto grau de transformação, que é estrutural e química.

A serapilheira de um solo florestal está sujeita a inúmeros fatores, dos quais resulta a decomposição e a consequente mineralização do material orgânico. A entrada de material pela deposição da serapilheira e a saída, ou transformação, pela decomposição, em geral ocorrem quase simultaneamente, quando se trata de floresta natural. Não ocorre da mesma forma com a serapilheira de P. taeda, que se processa lentamente, devido à composição das acículas (BURGUES; RAW, 1971). As folhas das angiospermas e as acículas de pínus constituem a fração mais significativa do material biogênico florestal e anual produzido (PROCTOR, 1983). 
Ovington (1958), citado por Osaki (2006), estudando as coníferas, observou que suas acículas possuem alto teor de carbono e baixo de nitrogênio, cuja relação $\mathrm{C} / \mathrm{N}$ é alta, o que promove o acúmulo de matéria orgânica na superfície. Valores mais elevados para o pínus foram encontrados também por Barth (1980) na superfície, evidenciando que o acúmulo tenha sido provavelmente devido à contínua queda de acículas. Portanto, é possível verificar que o tipo de material influencia na diversificação da decomposição e dos decompositores no solo (BURGUES; RAW, 1971; McLEAD et al., 1979; BAATH; ARNEBRANT, 1994). Estudando o efeito da matéria orgânica e a reciclagem de nutrientes em florestas tropicais de Pinus palustris Mill., esses autores observaram que houve uma diminuição no crescimento das árvores quando se removia a serapilheira, concluindo que isso se deve à falta de nutrientes e ao rompimento do ciclo hidrológico, que não se mantém quando não há material, ou seja, matéria orgânica.

Em geral, a decomposição ocorre rapidamente em regiões tropicais e subtropicais com excesso de umidade (ANDRAE, 1978). As florestas, tanto tropicais como subtropicais deciduais, perdem suas folhas no início da estação seca, ou seja, inverno e início da primavera, quando reduz a atividade de decomposição, resultando no desenvolvimento de horizontes orgânicos (SWIFT et al., 1979). Essa mesma característica de temperatura ocorre na floresta classificada como Ombrófila Mista, em que a maior produção de serapilheira, em geral, se dá nessas estações do ano, quando há maior precipitação, isto é, nos meses de verão e primavera. Tudo indica que é uma estratégia para renovar as folhas, resultante da grande quantidade de água e radiação existente nesses períodos (TOLEDO et al., 2002).

A atividade microbiológica é maior na serapilheira fresca, decrescendo posteriormente em processos mais avançados do material. Em geral, as folhas de espécies perenifólias são mais resistentes à decomposição do que as das espécies caducifólias, bem como a serapilheira de angiospermas, que se decompõe mais rapidamente do que a de gimnospermas. Os carboidratos são decompostos rapidamente, enquanto que os polifenóis são menos palatáveis aos organismos, sendo, pois, lentamente decompostos (HAAG et al., 1985; SANTOS, 1989).

A quantidade e a composição química da serapilheira de povoamento de $P$. taeda (acículas), além das condições edafoclimáticas, dependem da idade da floresta, densidade e variação sazonal e anual da produção de serapilheira pelos elementos arbóreos, assim como do manejo empregado e da metodologia de avaliação usada. Em solos sob povoamentos de espécies do gênero Pinus sp. ocorre a formação de uma espessa camada de material orgânico, o qual é formado, em sua maior parte, de acículas (70\%), sendo o restante por estruturas reprodutivas, ramos, cascas e pedaços do caule, os quais podem apresentar uma lenta decomposição, porém com uma significativa carga de nutrientes, sendo devolvidos através desse material ao solo. Outra função da camada de serapilheira composta de acículas, que se acumula sob o povoamento de pínus, é o de funcionar como uma esponja sobre o solo, com capacidade de reter a água da chuva e reduzir a evaporação e as variações bruscas de temperatura do solo, portanto, de agir como isolante térmico. Além disso, reduz a erosão, melhorando a estrutura do solo e promovendo a ciclagem dos nutrientes através dos microrganismos (FERREIRA, 2004).

Quanto à espessura das camadas de serapilheira de Pinus taeda, essa é bem maior quando comparada à da Floresta Ombrófila Mista $(1,0-2,0 \mathrm{~cm})$, possuindo uma média de 10,0-15,5 cm de espessura (GOLFARI, 1963; MIROV, 1967). De acordo com Chaves e Correa (2005), a maior resistência das acículas à decomposição sugere que não há um aumento real da matéria orgânica no solo e que a atividade efetiva da população microbiana ocorre na matéria orgânica depositada anteriormente ao plantio.

Archibold (1995), avaliando a biomassa e os nutrientes de uma serapilheira florestal natural, constatou que menos de 5\% da biomassa podem conter cerca de $14 \%$ do estoque de nutrientes, e é nesse ambiente que a população da biota e microbiota se desenvolve melhor, favorecida pela existência de matéria orgânica armazenada.

$\mathrm{Na}$ Costa Rica, alguns estudiosos constataram que as folhas demoraram 24 semanas para se decompor, enquanto que outros componentes da serapilheira, que tinham menos de $3 \mathrm{~cm}$ de diâmetro, demoraram 31 semanas. No mesmo estudo, em árvores mortas com mais de $22 \mathrm{~cm}$ de DAP, levou cerca de 13 anos para se decompor (GOLLEY et al., 1978).

Essas camadas de serapilheira ficam sobrepostas em diferentes graus de decomposição e recebem a denominação de horizonte L (lixiviação), que se compõe de folhas recém-caídas, inteiras e não pisoteadas ou usufruídas pela fauna do solo; horizonte $\mathrm{F}$ (fermentação), que possui atividade biológica intensa, devido à fragmentação causada pela fauna do solo e à degradação bioquímica feita pelos microrganismos, no qual existe grande quantidade de raízes finas que absorvem os elementos nutricionais 
liberados da matéria orgânica; e horizonte H (humificação), que apresenta material amorfo e escuro, decorrente da atividade no horizonte anterior (F) (MASON, 1980; SANTOS; CAMARGO, 1999).

O objetivo deste estudo foi avaliar a distribuição horizontal e vertical da população de fungos em duas formações florestais: Floresta Ombrófila Mista e povoamento florestal com P. taeda, no verão e no inverno.

\section{MATERIAL E MÉTODOS}

Os experimentos foram conduzidos no município de Tijucas do Sul, PR, Brasil, localizado no VIVAT Floresta entre as coordenadas geográficas $25^{\circ} 56^{\prime} 00^{\prime} \mathrm{S}, 49^{\circ} 10^{\prime} 00^{\prime}$ ' W, com altitude variando entre 856 e 1.350 m (LIEBSCH; ACRA, 2004; GANHO; MARINONI, 2006).

O clima local, segundo a classificação de Köppen, é designado como $\mathrm{Cfb}$, definido como subtropical úmido mesotérmico, com verão fresco. $\mathrm{O}$ mês mais frio apresenta temperatura média inferior a $18{ }^{\circ} \mathrm{C}$ e o mais quente temperatura média inferior a $22{ }^{\circ} \mathrm{C}$. A área experimental apresenta precipitação média anual de $1.400 \mathrm{~mm}$, está sujeita a geadas severas e não apresenta, em anos normais, estação seca (INSTITUTO AGRONÔMICO DO PARANÁ (IAPAR), 1978).

Na Floresta Ombrófila Mista, a topossequência identificada foi plana, meia encosta e topo (colina). O relevo é variável: plano (0-3\% de declividade), solo aluvial, predominando o ARGISSOLO VERMELHO-AMARELO Distrófico típico, de textura média e profundidade entre 2,0-2,5 m (EMPRESA BRASILEIRA DE PESQUISA AGROPECUÁRIA (EMBRAPA), 2006). Na zona de meia encosta, considerado ondulado e solo coluvial, foram constatados declives de $12-18 \%$, predominando a associação de CAMBISSOLO HÁPLICO Alumínico argissólico com ARGISSOLO VERMELHOAMARELO Distrófico câmbico.

Na zona considerada topo (colina), ou seja, solo eluvial, a declividade constatada foi superior a $18 \%$, isto é, em geral áreas com $20-22 \%$ de declividade, onde predominou a associação CAMBISSOLO HÁPLICO Distrófico típico com NEOSSOLO Litólico típico, com alguns afloramentos de rochas.

O relevo do povoamento florestal de $P$. taeda é plano, sendo o solo classificado como CAMBISSOLO com A proeminente húmico, em toda a área (EMBRAPA, 2006).

O delineamento utilizado foi o de blocos ao acaso em arranjo fatorial $3 \times 2$, três profundidades (serapilheira, zona de transição e solo) e duas estações do ano (inverno e verão), com três repetições.

Os experimentos foram implantados em duas áreas, o primeiro sob Floresta Ombrófila Mista e o segundo em povoamento com Pinus taeda.

Foram estabelecidos três blocos de igual tamanho em cada formação, cada um deles com $10.000 \mathrm{~m}^{2}$ de área, sendo eles subdivididos em cem subunidades amostrais de $10 \times 10 \mathrm{~m}$, com área de $100 \mathrm{~m}^{2}$ cada uma. A coleta de amostras foi realizada em cinco dessas subunidades amostrais sorteadas ao acaso dentro de cada bloco, formando uma amostra composta, e em três profundidades: serapilheira, zona de transição e solo.

Previamente à aplicação da análise de variância, foi efetuado o teste de homogeneidade de variâncias dos tratamentos. Usou-se o teste de Hartley, também conhecido como teste $\mathrm{F}_{\max }$, usado para as situações quando se tem 3 ou mais grupos. O teste é aplicado tomando-se a variância de maior valor e a dividindo pela de menor valor. Tal razão é comparada com o valor crítico de uma distribuição probabilística de $\mathrm{F}_{\max }$. Esse é um teste de fácil aplicação e pressupõe, naturalmente, que os grupos testados procedem de dados normalmente distribuídos e um igual número de elementos nos grupos sob teste. Significâncias são atestadas ao nível de $95 \%$ ou $99 \%$ de probabilidade, quando o valor calculado de $\mathrm{F}_{\max }$ para os grupos exceder o valor tabelar explicitado para os níveis de significância usados para o teste.

O teste estatístico usado para comparação de médias após a análise de variância foi o de Tukey, de único intervalo para comparação de pares de médias, e, na prática, funciona essencialmente como o teste " $\mathrm{t}$ ", porém com aplicação corretiva do erro experimental. As médias, para facilitar a avaliação de significância, foram ordenadas de maneira crescente e testadas duas a duas, aos níveis de 95 e $99 \%$ de probabilidade, até se detectar significância, quando tais diferenças excedem o valor $q_{s}$ de Tukey.

As amostras simples foram coletadas em área de $1 \mathrm{~m}^{2}$, com auxílio de uma pinça grande, sem tocá-las diretamente com as mãos, para evitar contaminação. Elas foram misturadas e homogeneizadas, para formar uma amostra composta, que, após identificadas por bloco, foram encaminhadas para o Laboratório de Análise da Pontifícia Universidade Católica do Paraná, visando a determinação das unidades formadoras de colônias (UFC. $\mathrm{g}^{-1}$ de solo) de fungos. 
A avaliação da população de fungos foi realizada pela técnica de diluição decimal em série e contagem em placas de Petri descartáveis. Foram feitas diluições decimais em série a partir de $10 \mathrm{~g}$ de solo úmido, o qual foi previamente pesado e, após, quantificada a sua umidade. Em seguida, procedeu-se ao peneiramento do solo em malha $2 \mathrm{~mm}$, o qual foi transferido para recipientes contendo $90 \mathrm{ml}$ de solução salina em frasco tampado.

Três esferas de vidro esterilizadas de $6 \mathrm{~mm}$ de diâmetro foram colocadas em cima do recipiente como tampa. Agitou-se a $100 \mathrm{rpm}$ a suspensão formada de solo mais solução, por 30 minutos, em agitador mecânico de movimentação circular. Dessa suspensão, procedeu-se às diluições decimais seriadas de $10^{-2}, 10^{-3}$ e $10^{-4}$. Em seguida, foi plaqueado $0,1 \mathrm{~mL}$ por placa das diluições correspondentes a cada grupo de microrganismos, ou seja, espalhou-se o inóculo de forma uniforme na placa de Petri, usando-se a alça de Drigalski, incubando-se a $25{ }^{\circ} \mathrm{C}$ com as placas invertidas. Após o sexto dia de incubação, iniciou-se a contagem das unidades formadoras de colônias (UFC. $\mathrm{g}^{-1}$ ) de fungos.

Para determinação da população de fungos, foram utilizadas as diluições $10^{-2}, 10^{-3}$ e $10^{-4}$, e o meio de cultura empregado foi o de Martin (MENZIES, 1965).

Para a contagem dos fungos, foram utilizadas as diluições $10^{-2}, 10^{-3}$ e $10^{-4}$. Após um período de incubação de 4 a 8 dias no verão e 5 a 9 dias no inverno, realizou-se a contagem do número de unidades formadoras de colônias de fungos (UFC). Foram, ainda, selecionadas as diluições que fornecessem valores até 250 UFC.placa ${ }^{-1}$.

\section{RESULTADOS E DISCUSSÃO}

A homogeneidade das variâncias nas diferentes profundidades foi avaliada por meio do teste de Hartley. Para a realização da análise de variância, os dados de população de fungos foram logaritmizados, e a comparação das médias do número de microrganismos foi realizada por meio da análise de variância, quando suas variâncias resultaram homogêneas. Adicionalmente, quando verificada a diferença entre as médias, realizou-se o teste de Tukey.

A análise de variância para a população de fungos na Floresta Ombrófila Mista está apresentada na tabela 1. Observa-se, na tabela 1, que foram encontradas diferenças estatísticas para a profundidade, estação e interação para essa formação florestal.

Tabela 1. Análise de variância de fungos em três profundidades (serapilheira, zona de transição e solo) e duas estações do ano (inverno e verão), na Floresta Ombrófila Mista, Tijucas do Sul/PR, Brasil.

Table 1. Variance analisys of the fungi population $\left(\mathrm{UFC} \mathrm{g}^{-1}\right.$ ), in the Subtropical Ombrophilous Forest, in tree depths (litter, transition zone and soil) and in two seasons (winter and summer), in the municipality of Tijucas do Sul/PR, Brazil.

\begin{tabular}{lcccc}
\hline Fonte & GL & SQ & QM & F \\
\hline Bloco & 2 & 1,00 & 0,50 & $0,16^{\text {ns }}$ \\
A: Profundidade & 2 & 42,85 & 21,42 & $6,78^{*}$ \\
B: Estação & 1 & 22,47 & 22,47 & $7,12^{*}$ \\
Interação AB & 2 & 94,97 & 47,48 & $15,04^{* *}$ \\
Resíduo & 10 & 31,58 & 3,16 & \\
Total & 17 & 192,87 & & \\
*: significância a 95\% de probabilidade; **: significância a 99\% de probabilidade; ${ }^{\text {ns: }}$ não significância.
\end{tabular}

Os valores verificados para a população de fungos nas três profundidades (serapilheira, transição e solo) e duas estações do ano avaliadas (inverno e verão) podem ser visualizados na figura 1.

Não foi verificada diferença significante ao nível de $95 \%$ de probabilidade entre as médias da população entre os blocos, mostrando que foram homogêneos. Foi verificada diferença estatisticamente significativa entre as médias de fungos, ao nível de 95\% de probabilidade, na Floresta Ombrófila Mista, entre as profundidades e estações do ano, bem como nas interações ao nível de $99 \%$.

$\mathrm{Na}$ figura 1 é possível observar a diferença verificada na análise de variância entre as profundidades e estações do ano na Floresta Ombrófila Mista. Os resultados mostraram que houve diferença estatisticamente significava ao nível de $95 \%$ de probabilidade entre as profundidades estudadas, sendo a maior população de fungos observada na serapilheira, 59,08 x $10^{5}$ UFC. ${ }^{-1}$, que diferiu e foi superior à população da transição $\left(26,58 \times 10^{5} \mathrm{UFC}^{-1} \mathrm{~g}^{-1}\right)$ e no solo $\left(0,56 \times 10^{5} \mathrm{UFC} \cdot \mathrm{g}^{-1}\right)$. 


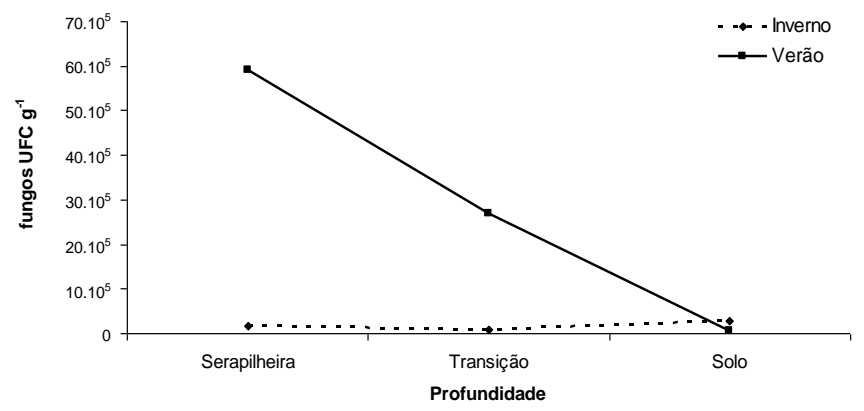

Figura 1. População média de fungos em três profundidades (serapilheira, zona de transição e solo) e duas estações (inverno e verão) no ecossistema Floresta Ombrófila Mista, em Tijucas do $\mathrm{Sul} / \mathrm{PR}$.

Figure 1. Fungi population in three depths (litter, transition zone and soil) and two seasons (winter and summer), in Mixed Ombrophilous Forest, Tijucas do Sul/PR, Brazil.

Os resultados mostram que os materiais depositados na serapilheira favorecem o desenvolvimento de fungos que são responsáveis pela decomposição da matéria orgânica de forma a utilizar os nutrientes para sua própria manutenção. Esse resultado é confirmado por Souto (2006), que, estudando o comportamento do fungo do solo, relatou aumento da população a partir de fevereiro, devido ao acréscimo de matéria orgânica.

O período de inverno apresentou índice pluviométrico médio de $54,0 \mathrm{~mm}$, e nessa estação verificou-se menor população de fungos, com $1,70 \times 10^{5} \mathrm{UFC}^{-1} \mathrm{~g}^{-1}$ de solo, diferindo estatisticamente da população observada no período de verão, que apresentou $28,85 \times 10^{5}$ UFC.g $^{-1}$ de solo e teve $114,2 \mathrm{~mm}$ de chuva.

Resultados semelhantes foram obtidos em estudo realizado na determinação da população fúngica, a qual apresentou decréscimos consideráveis, devido ao baixo conteúdo de água no solo nos meses de menor precipitação (SOUTO, 2006). Segundo Ghizelini (2005) e Moreira e Siqueira (2002), a temperatura tem grande influência na densidade populacional de fungos no solo. A temperatura afeta não só as reações fisiológicas e metabólicas das células, como também as características físico-químicas do ambiente em que vivem. No presente trabalho, entretanto, verificou-se que a variação de temperatura entre as estações foi pequena, sendo que no verão a temperatura média foi de $22,1{ }^{\circ} \mathrm{C}$ e no inverno de $19,4{ }^{\circ} \mathrm{C}$, variação que pode ser ainda menor no solo, considerando o dossel das florastas.

\section{Povoamento Florestal com Pinus taeda}

A análise de variância para a população de fungos no povoamento florestal com Pinus taeda está apresentada na tabela 2 .

Tabela 2. Análise de variância da população de fungos em três profundidades (serapilheira, zona de transição e solo) e duas estações do ano (inverno e verão), no povoamento florestal com $P$. taeda, Tijucas do Sul/PR, Brasil.

Table 2. Variance analisys of the fungi population (UFC g ${ }^{-1}$ ), in the P. taeda manmade forest, in tree depths (litter, transition zone and soil) and in two seasons (winter and summer), in the municipality of Tijucas do Sul/PR, Brazil.

\begin{tabular}{lcccc}
\hline Fonte & GL & SQ & QM & F \\
\hline Bloco & 2 & 2,44 & 1,22 & $0,29^{\mathrm{ns}}$ \\
A: Profundidade & 2 & 35,17 & 17,58 & $4,19^{*}$ \\
B: Estação & 1 & 1,89 & 1,89 & $0,45^{\mathrm{ns}}$ \\
Interação AB & 2 & 27,50 & 13,75 & $3,28^{\mathrm{ns}}$ \\
Resíduo & 10 & 41,97 & 4,20 & \\
Total & 17 & 108,96 & & \\
*: significância a 95\% de probabilidade; **: significância a 99\% de probabilidade; ${ }^{\text {ns }}$ : não significância.
\end{tabular}


A população de fungos observada sob os fatores estação e interação não apresentaram diferença significativa a $95 \%$ de probabilidade entre as médias, entretanto houve diferença entre as médias das profundidades.

O valor obtido para a população de fungos na serapilheira foi $10,90 \times 10^{5}$ UFC.g-1 , sendo estatisticamente superior ao nível de $95 \%$, diferente do solo, que apresentou 1,68 x $10^{5}$ UFC.g $^{-1}$ de solo, enquanto que a zona de transição não foi diferente estatisticamente do solo e da serapilheira $\left(9,17 \times 10^{5} \mathrm{UFC} \cdot \mathrm{g}^{-1}\right)$.

Conforme afirmaram Ferreira e Cruz (1991) e Alexander (1980), à medida que as fontes de carbono para decomposição vão desaparecendo, com consequente redução na quantidade de energia e de nutrientes para os microrganismos, vai sendo observada uma redução na atividade e na quantidade microbiana, de acordo com a profundidade. Foi exatamente o que ocorreu nos resultados para o verão obtidos neste experimento, conforme se pode observar na situação mostrada na figura 2 . Esse processo de redução na atividade dos fungos prossegue até atingir novo equilíbrio, com a quantidade de material que está sendo adicionada igual à que está sendo destruída. A explicação disso está basicamente no tipo de resíduo que foi adicionado e na composição do húmus. Isso explica que a quantidade, o tipo e a disponibilidade de material orgânico encontrado perfil adentro determinam a densidade populacional e a composição da população hetrotrófica, ou seja, de fungos que necessitam de substâncias orgânicas como fonte de energia e de carbono que o solo conterá. Foi exatamente o que ocorreu no presente trabalho, conforme está apresentado na figura 2.

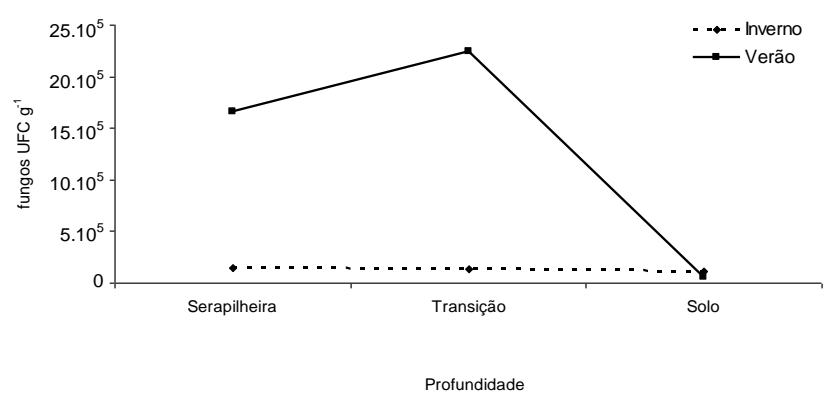

Figura 2. População média de fungos em três profundidades (serapilheira, zona de transição e solo) e duas estações (inverno e verão), no povoamento com P. taeda em Tijucas do Sul/PR.

Figure 2. Fungi population average in three depths (litter, transition zone and soil) and two seasons (winter and summer) in P. taeda. manmade Forest, Tijucas do Sul/PR, Brazil.

A figura 2 apresenta a diferença verificada pela análise de variância entre as profundidades no povoamento de pínus. Salienta-se que a adição de matéria orgânica favorece o desenvolvimento de fungos (CARDOSO, 1992). Alguns autores relatam que a deposição da serapilheira pode variar com a sazonalidade, devido às mudanças na temperatura e disponibilidade de água.

Estudando a população de fungos em duas profundidades de solo, 0-5 cm e 5-10 cm, Souto (2006) verificou maiores valores para a população de fungos na profundidade de $0-5 \mathrm{~cm}$. Do perfil do solo, a serapilheira, a zona de transição e a rizosfera são os lugares mais abundantes em fontes de alimentos e nutrientes, sendo essas áreas os locais ideais para o desenvolvimento do microrganismo.

Quando consideradas as estações do ano, estudos realizados por Ghizelini (2005) mostraram correlação entre temperatura média e população total de fungos, enquanto que o mesmo não foi observado para a precipitação pluviométrica.

Em relação às diferenças observadas no índice pluviométrico para inverno $(54 \mathrm{~mm})$ e verão $(114,2 \mathrm{~mm})$, os resultados obtidos no presente trabalho sugerem que a umidade no povoamento de Pinus taeda também não influenciou a população fúngica. Os resultados mostraram que houve diferença estatisticamente significava ao nível de $95 \%$ de probabilidade entre as profundidades estudadas, sendo a maior população de fungos observada na serapilheira $\left(16,55 \times 10^{5} \mathrm{UFC} \cdot \mathrm{g}^{-1}\right)$, que diferiu e foi superior à população da transição $\left(22,44 \times 10^{5} \mathrm{UFC} \cdot \mathrm{g}^{-1}\right)$ e no solo $\left(0,59 \times 10^{5} \mathrm{UFC} \cdot \mathrm{g}^{-1}\right)$.

Enquanto Ghizelini (2005) relatou correlação positiva para a temperatura, no presente trabalho não foi observada interação entre a comunidade fúngica e a estação do ano. Entretanto, é necessário 
considerar a variação de temperatura ocorrida naquele e neste trabalho $\left(19,4{ }^{\circ} \mathrm{C}\right.$ para o inverno e $22,1{ }^{\circ} \mathrm{C}$ para o verão). No primeiro caso, estudado por Ghizelini (2005), a variação foi de aproximadamente $14{ }^{\circ} \mathrm{C}$, e no segundo foi de apenas $7{ }^{\circ} \mathrm{C}$. Além dessa menor variação de temperatura, deve-se considerar que a serapilheira de Pinus pode funcionar como um regulador de temperatura do meio, devido à sua maior espessura e homogeneidade. Isso gera um ambiente competitivo entre os microrganismos e pouco variável do ponto de vista físico e microclimático.

\section{Interação}

Foi verificada diferença significativa na interação entre profundidade e estação ao nível de $99 \%$ de probabilidade, na Floresta Ombrófila Mista, segundo a análise de variância, enquanto que no povoamento de Pinus não foi verificada essa tendência. Os resultados mostraram que houve interação entre os fatores verão e serapilheira e para os fatores inverno e solo na Floresta Ombrófila Mista.

Assim, solos de florestas naturais, como a Floresta Ombrófila Mista, dependem da disponibilidade natural de material carbonado do sistema e da temperatura.

\section{CONCLUSÕES}

- Na Floresta Ombrófila Mista e no povoamento de Pinus taeda, o aumento da população de fungos se deveu à maior oferta de matéria orgânica na serapilheira.

- No verão, a maior umidade e temperatura favoreceram o incremento da população de fungos, tanto para a Floresta Ombrófila Mista como para o povoamento de Pinus, mostrando maior intensidade na dinâmica de nutrientes.

- Os resultados analisados na Floresta Ombrófila Mista, para o verão, mostram que os materiais depositados na serapilheira favorecem o desenvolvimento de fungos que são responsáveis pela decomposição da matéria orgânica, de forma a utilizar os nutrientes para sua própria manutenção, decrescendo à medida que se avalia tal população nas diferentes profundidades, até se atingir o solo, razão pela qual se detectou alta significância na interação dos fatores estação do ano com profundidade.

- Na avaliação dos resultados observados no povoamento de Pinus taeda, conquanto se observa também nessa formação maior desenvolvimento de fungos no verão do que no inverno, não se observou interação dos fatores estação do ano com profundidade, devido sua maior população ocorrer na área de transição entre serapilheira e solo, fato este explicado pelo maior tempo necessário no processo de decomposição das acículas, quando se torna mais efetiva a atuação da população fúngica.

- A variabilidade horizontal da população de fungos nas duas formações mostrou-se altamente significativa, atestada pela aplicação do teste de Hartley, razão pela qual foi necessário efetuar a transformação logarítmica dos dados para a realização da comparação de médias pela análise de variância. Tal variabilidade está fortemente associada à disponibilidade local de matéria orgânica na serapilheira.

\section{REFERENCIAS}

ALEXANDER, M. Introducción a la microbiologia del suelo. México, D.F.: Libros y Editoriales, 1980. 491.

ANDRAE, F. H. Ecologia Florestal. Santa Maria: UGFSM, 1978. 230 p.

ARCHIBOLD, O. W. Ecology of world vegetation. Canadá: Ed. Chapman Hall, 1995. 510 p.

BAATH, E.; ARNEBRANT, K. Growth rate and response of bacterial communities to $\mathrm{pH}$ in limite and ash treated forest soils. Soil Biology \& Biochemistry, Oxford. n. 8, p. 995 - 1001. 1994.

BALOTA, E. L.; ANDRADE, D. S. Microrganismos e processos biológicos no sistema plantio direto. In: SIQUEIRA. J. O. et al. Inter-relação fertilidade, biologia do solo e nutrição de plantas. Viçosa: SBCS; Lavras: UFLA/DCS, 1999. p. 487 - 508. 
BARTH, R. C. Influence of Pinyon pine trees on soil. Science American Journal. v. 44, p. 112 - 114. 1980.

BRITEZ, R. M. Ciclagem de nutrientes minerais em duas florestas da planície litorânea da Ilha do Mel, Paranaguá, PR. 238 f. Dissertação (Mestrado em Agronomia) - Setor de Ciências Agrárias da Universidade Federal do Paraná, Curitiba, 1994.

BROWN, S.; LUGO, A. The storage and production of organic matter in tropical forest and their role in the global carbon cycle. Biotropica, Washington D.C., v. 14, n. 3, p. 161 - 187, 1982.

BURGUES, A.; RAW, F. Biologia del suelo. [s.1.]: Omega, 1971. 696 p.

CALBRIX, R.; LAVAL, K.; BARRAY, S. Analysis of the potential functional diversity of the bacterial community in soil: A reproductive procedure using sole-carbon-source utilization profile. Eur. J. Soil Biol., 41:11 - 20, 2005.

CAMPOS, J. B. Biodiversidade - Reserva Legal: importância e conservação. Diretoria de Biodiversidade e Áreas Protegidas do Instituto Ambiental do Paraná (DIBAP). 2008. Curso de capacitação de profissionais. PROCREA.

CARDOSO, E. J. B. N.; TSAI, S. M.; NEVES, M. C. P. (ed.). Microbiologia do solo. Campinas: Sociedade Brasileira do Solo, 1992. 360 p.

CATTELAN; A. J.; TORRES; E.; SPOLADORI, C. L. Sistemas de preparo com a sucessão trigo/soja e os microrganismos do solo, em Londrina. Revista Brasileira de Ciência do Solo, Campinas, v. 21, p. $303-311,1997$.

CHAVES, R. de Q.; CORREA, G. F. Macronutrients in the soil - Pinus caribaea Morelet system with yellowing of the needles followed by senescence and death. Revista Árvore, v. 29, n. 5, p. 691 - 700, 2005.

DIONÍSIO, J. A. Atividades microbianas em diferentes sistemas de cultivo de Eucalyptus grandis (W. Hill ex Maiden). 90 f. Tese (Doutorado em Engenharia Florestal) - Setor de Ciências Agrárias, Universidade Federal do Paraná, Curitiba, 1996.

EMPRESA BRASILEIRA DE PESQUISA AGROPECUÁRIA (EMBRAPA). Sistema Brasileiro de Classificação de Solos. 2. ed. Brasília: Empresa Brasileira de Pesquisa Agropecuária, 2006. 306 p.

FERREIRA, C. Conservação e manejo sustentável de ecossistemas florestais: relatório de atividades PELD - Pesquisas Ecológicas de Longa Duração) - SITIO 9. Bioma Floresta de Araucária e suas transições. (2004).

FERREIRA, M. E.; CRUZ, M. C. P. Micronutrientes no solo. In: FERREIRA, M. E.; CRUZ, M. C. P. (eds.) Micronutrientes na agricultura. Piracicaba: POTAFOS/CNPq, 1991. p. 131 - 157.

FREIRE, J. R. J. Microbiologia do solo. Porto Alegre: UFRGS, Departamento de Solos, Faculdade de Agronomia, 1975. 234 p. Apostila.

GANHO, N. G.; MARINONI, R. C. A variabilidade espacial das famílias de Coleoptera (Insecta) entre fragmentos de Floresta Ombrófila Montana (Bioma Araucária) e plantação de Pinus elliottii Engelmann, no Parque Ecológico Vivat Floresta, Tijucas do Sul, Paraná, Brasil. Revista Brasileira de Zoologia. 23 (4):1159 - 1167, dezembro 2006.

GHIZELINI, A. M. Sucessão de fungos em acículas de Pinus taeda em decomposição. 2005. $61 \mathrm{f}$. Dissertação (Mestrado em Ciências Florestais) - Setor de Ciências Agrárias, Universidade Federal do Paraná, Curitiba, 2005.

GOLFARI, L. Climatic requirements of tropical and subtropical conifers - the behavior of certain exotic pines mainly in Latin America. Unasylva - FAO, v. 17, n. 1, p. 33 - 42, 1963.

GOLLEY, F. B.; McGINNIS, J. T.; CLEMENTS, R. G.; CHILD, G. I.; DUEVER, M. J. Ciclagem de minerais em um ecossistema de floresta tropical úmida. São Paulo: E.P.U. EDUSP, 1978. 
GONÇALVES, J. L. M.; DEMATTÊ, J. L. I.; COUTO, H. T. Z. Relações entre a produtividade de sítios florestais de Eucalyptus grandis e Eucalyptus saligna com as propriedades de alguns solos de textura arenosa e média no estado de São Paulo. IPEF. Piracicaba, n. 43/44, p. 24 - 39, 1990.

HAAG, H. P.; VALERA, F. P.; CHIARANDA, R.; KIKUTI, P.; CHAVEZ, J. M.; DONALD, G. L. de F.; RIZZO, L. T. B.; RUEDA, J. L. Ciclagem de nutrientes em florestas tropicais. Campinas: Fundação Cargill, 1985. $144 \mathrm{p}$.

HARRIS, R. F. Effect of water potential on microbial growth and activity. In: PARR, J.; GARDNER, W. R.; ELLIOT, L. F. (ed.). Water potential relation in soil microbiology. Madison: Soil Sciences Society American, 1981.

HEANEY, A.; PROCTOR, J. Chemical elements in litter in forests on Volcán Barva, Costa Rica. In: PROCTOR, J. Mineral nutrients in tropical forest and savanna ecosystems. [s.l.]: Blakwell Sci, Publications, 1989. p. 255 - 271.

INSTITUTO AGRONÔMICO DO PARANÁ (IAPAR). Cartas climáticas básicas do estado do Paraná. Londrina, 1978. 41 p.

INSTITUTO AMBIENTAL DO PARANÁ (IAP). (www.iap.gov.br). Dados sobre plantios florestais no Paraná. 2006.

LIEBSCH, D.; ACRA, L. A. Riqueza de espécies de sub-bosque de um fragmento de Floresta Ombrófila Mista em Tijucas do Sul, PR. Ciência Florestal, Santa Maria, v. 14, n 1, p. 67 - 76.2004.

MASON, C. F. Decomposição. São Paulo, EPU/EDUSP, 1980. 62 p.

McLEAD, K. W.; SHERROD JR., C.; PORCH, T. E. Response of longleaf pine plantation to litter removal. Forest, Ecology and Management, v. 2, p. 1 - 12, 1979.

MENZIES, J. D. Fungi. In: BLACK, C. A. ed. Methods of soil analysis. Madison: American Society of Agronomy, v. 2, cap. 107, 1502 - 1505. 1965.

MIROV, N. T. The genus pinus. New York: Ronald Press, 1967. 602 p.

MOREIRA, F. M.; SIQUEIRA, J. O. Microbiologia e bioquímica do solo. Lavras: Editora UFLA, 2002. $626 \mathrm{p}$.

OSAKI, F. (eds.). Olericultura integrada: desafios da olericultura moderna, alternativas e soluções para o cultivo de hortaliças. Curitiba, 2006. 516 p.

OVINGTON, J. D. Studies of the development of woodland conditions under different trees. J. Eccl. n. 46, p. 127 - 142. 1958.

PAUL, E. A.; CLARK, F. E. (eds.). Soil microbiology and biochemistry. New York: Academic Press, 1989. $273 \mathrm{p}$.

PEÑA, M. L. P. Indicadores microbiológicos de solo na avaliação da recuperação de área degradada de floresta Ombrófila Densa das Terras Baixas no Litoral Paranaense - Brasil. Dissertação (Mestrado em Ciências Florestais) - Setor de Ciências Agrárias, Universidade Federal do Paraná, Curitiba, 2002.

PROCTOR, J. Tropical Forest litterfall. I. Problems of data comparison. In: SUTTON, S. L.; WHITMORE, T. C.; CHADWICK, A. C. (eds.). Tropical Rain Forest and Management. Oxford: Blackwell Scientific Publications, 1983. p. 267 - 273.

REISSMANN, C. B.; WISNIEWSKI, C. Aspectos nutricionais de plantios de Pinus. In: GONÇALVEZ, J. L. M.; BENEDETTI, V. (eds.). Nutrição e fertilização florestal. Piracicaba: Piracicaba, v. 1, p. 135 $136,2000$. 
RIGOBELO, E. C.; NAHAS, E. Seasonal fluctuations of bacterial population and microbial activity in soils cultivated with eucalyptus and pinus. Sci. agric. (Piracicaba, Braz.), ene./feb. 2004, v. 61, n. 1, p. 88 - 93. ISSN 0103-9016.

SAMPAIO, E. V. S. B.; DALL'OLIO, A.; NUNES, K. S.; PINTO, E. E. A model of litterfall, litter layer losses and mass transfer in a humid tropical forest at Pernambuco, Brazil. Journal of Tropical Ecology, Cambridge, v. 9, p. 291 - 301, 1993.

SANTOS, G. A.; CAMARGO, F. A. O. Fundamentos da matéria orgânica do solo: ecossistemas tropicais e subtropicais. Porto Alegre: Genesis, 1999.

SANTOS, V. D. dos. Ciclagem de nutrientes minerais em Mata Tropical Subcaducifólia dos Planaltos do Paraná (Parque Estadual Vila Rica do Espírito Santo - Fênix/PR). 387 f. Tese (Doutorado em Ecologia) - Universidade de São Carlos, São Carlos, SP, 387 p. 1989.

SELLE, G. L. Ciclagem de nutrientes em ecossistemas florestais. Biosci. Journal. Uberlândia, v. 23, n. 4, p. 29 - 39. out.-dez. 2007.

SOUTO, P. C. Acumulação e decomposição da serapilheira e distribuição de organismos edáficos em área de caatinga na Paraíba, Brasil. 110 f. 2006. Tese ( Doutorado em Biologia) - UFPB, 2006.

SWIFT, M. J.; HEAL, O. W.; ANDERSON, J. M. (eds.). The influence of resource quality on decomposition processes. In: Decomposition in interrestrial ecosystems. Berkeley: University of California Press, 1979. p. 118 - 166.

TOLEDO, L. O.; PEREIRA, M. G.; MENEZES, C. E. G. Produção de serapilheira e transferência de nutrientes em florestas secundárias localizadas na região de Pinheiral, RJ. Ciência Florestal, Santa Mariana, v. 12, n. 2, p. 9 - 16, 2002.

VALPASSOS, M. A. R.; MALTONI, K. L.; CASSIOLATO, A. M. R.; NAHAS, E. Recovery of soil microbiological properties in a degraded area planted with Corymbia citriodora and Leucaena lecocephala. Sci. Agric. Piracicaba, v. 64, n. 1, p. 68 - 72, jan.-feb. 2007. 
